\title{
Viewpoints of Nurses toward Prosocial Tendencies at the Teaching Hospitals Affiliated to Iran University of Medical Sciences
}

\author{
Negareh Taleghani ${ }^{1}$, Marjan Mardani Hamooleh ${ }^{2}$, Naimeh Seyedfatemi $^{3}$, Hamid Haghani ${ }^{4}$
}

\begin{abstract}
Background \& Aims: Prosocial tendencies are aimed at improving the conditions of the recipient of aids, and the motivation of the individual is not to fulfill professional obligations. On the other hand, the recipient of aid is not an organization, but rather a human. Prosocial tendencies result in psychological wellbeing in individuals, so that self-esteem would become positive, life satisfaction would increase, individuals would become socially empowered, and their empathy with the other community members would extend. In fact, these tendencies lay the basis for amicable relations with others, cause empathy and compassion toward others, and enhances the support of those in need. As a result, these tendencies lead to the social flourishing of individuals and enhance their power of moral reasoning. From a deeper perspective, it could be stated that the individuals harboring these tendencies enjoy higher social trust and ultimately have favorable psychosocial health. In contrast, those without these tendencies experience greater social anxiety and emotional exhaustion and may feel unable to help and empathize with others. Prosocial tendencies promote the professional satisfaction of employees, making them content with communicating with others, which in turn leads to kindness toward others, absence of depressive symptoms, and less occupational interrelations. Therefore, it is safe to say that it is essential for nurses to benefit from prosocial tendencies, especially when they are required to provide comprehensive patient care. Nurses need these tendencies to establish valuable and ethical relations with patients and their families, which will ultimately result in their own moral transcendence. The present study aimed to assess prosocial tendencies among nurses.

Materials \& Methods: This cross-sectional, descriptive study was conducted on 200 nurses employed in four teaching hospitals affiliated to Iran University of Medical Sciences (IUMS) in 2019. The participants were selected via quota sampling. Data were collected using a demographic form to measure the variables of age, gender, marital status, education level, work experience, ward of employment, employment status, type of work shift, and interest in the nursing profession. The other tool was the scale of prosocial tendencies, which has been designed by Carlo et al. The content validity method was used to assess the validity of the tool. For this purpose, the Persian and English versions of the tool were provided to five nursing professors, and their corrective comments were applied. Moreover, the Cronbach's alpha coefficient was used to evaluate the reliability of the instrument, which was estimated at 0.84 for the entire tool. Data analysis was performed in SPSS version 16 using descriptive statistics (frequency, percentage, mean, and standard deviation) and inferential statistics (independent t-test and analysis of variance), and the P-value of less than 0.05 was considered significant. The study protocol was approved by the Research Ethics Committee of IUMS.

Results: The mean total score of the prosocial tendencies of the nurses was $88.9 \pm 15.74$. Among the prosocial tendencies, unknown dimensions $(3.81 \pm 0.88)$, critical dimension $(3.72 \pm 0.92)$, emotional dimension $(3.72 \pm$ $1.1)$, compliant dimension (3.68 \pm 0.78$)$, and altruistic tendencies $(3.15 \pm 0.82)$ had the highest to the lowest mean
\end{abstract}

\footnotetext{
1. MS in Psychiatric Nursing, School of Nursing and Midwifery, Iran University of Medical Sciences, Tehran, Iran

2. Assistant Professor, Nursing Care Research Center, Department of Psychiatric Nursing, School of Nursing and Midwifery, Iran University of Medical Sciences, Tehran, Iran (Corresponding author) Tel: 09132864077 Email: mardanihamoole.m@iums.ac.ir

${ }^{3}$. Professor, Nursing Care Research Center, Department of Psychiatric Nursing, School of Nursing and Midwifery, Iran University of Medical Sciences, Tehran, Iran

${ }^{4}$. Instructor, Department of Biostatistics, School of Health, Iran University of Medical Sciences, Tehran, Iran
} 
scores, respectively. Furthermore, no significant correlations were observed between the demographic characteristics of the nurses and prosocial tendencies.

Conclusion: According to the results, the nurses believed that helping others was the most desirable among various prosocial tendencies as long as the recipients of aid are aware of the help. This could be attributed to the nature of the nursing profession, which is essentially a populist profession, with professionals seeking to provide services to the community members, even if they are unaware of the services. In this study, the prosocial tendencies in the altruistic dimension had the lowest mean score compared to the other dimensions. Given the importance of altruism in the nursing profession and the consequences of its lack, as well as the fact that in the present study, this prosocial tendency had the lowest status from the perspective of the nurses, related interventions are critical to promote this tendency in nurses. These interventions should be based on psychological training in this area. In the present study, no significant correlations were observed between the demographic characteristics of the nurses and their prosocial tendencies. However, further investigations are required in this regard to clarify the possible associations between the demographic characteristics of the nurses and their prosocial tendencies. In addition, nursing researchers are advised to conduct studies with a qualitative approach in order to identify prosocial tendencies and analyze the factors that facilitate and threaten these tendencies. In clinical nursing, the results of this study could help nursing managers to consider care models based on prosocial tendencies in the healthcare plans for nurses, and various dimensions of these tendencies could be the building blocks of such models. The use of non-probability sampling in this study could be considered a limitation since the nature of this method makes it difficult to generalize the findings.

Keywords: Prosocial Tendencies, Nurse, Care, Altruism

\section{Conflict of Interest: No}

How to Cite: Taleghani N, Mardani Hamooleh M, Seyedfatemi N, Haghani H. Viewpoints of Nurses toward Prosocial Tendencies at the Teaching Hospitals Affiliated to Iran University of Medical Sciences. Iran Journal of Nursing. 2019; 32(120):50-9.

Received: 13 Jul 2019

Accepted: 15 Oct 2019 


\title{
كرايشهاى اجتماعى مطلوب از ديدكاه ير ستار ان شاغل در مراكز آموزشى درمانى دانشكاه علوم يزشكى ايران
}

\author{
نغاره طالقانى '، مرجان مردانى حموله '، نعيمه سيدفاطمى"، حميد حقانىع
}

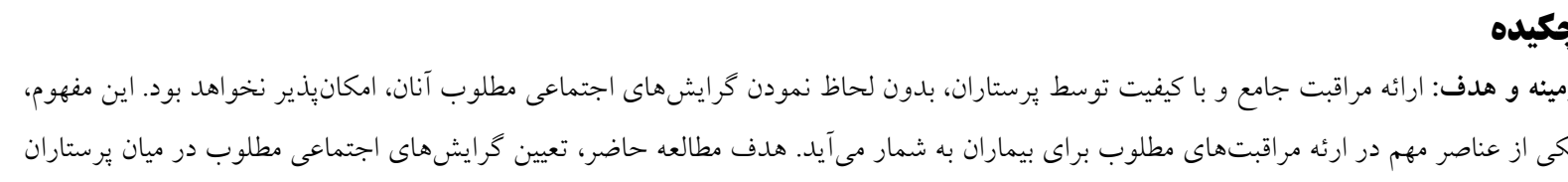

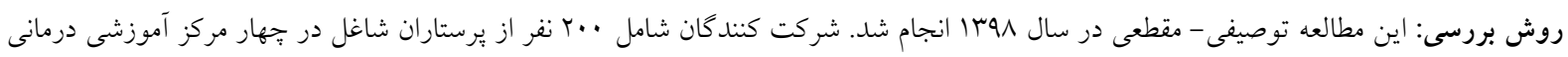

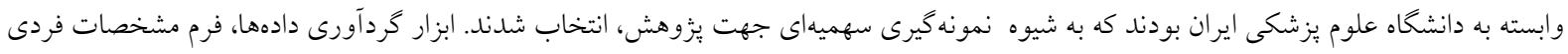

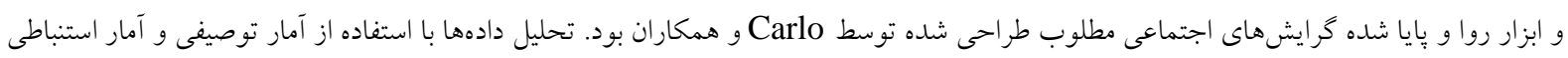

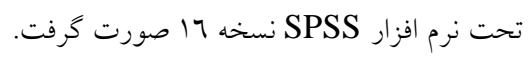

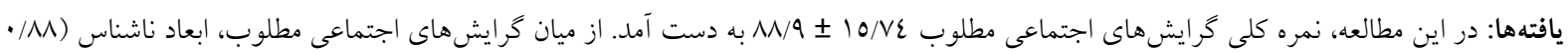
ت

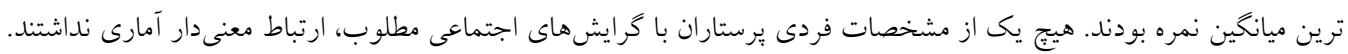

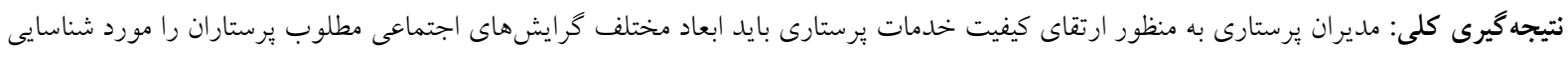

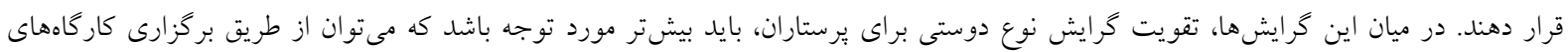

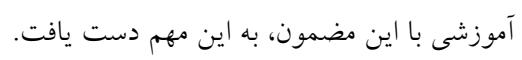

كليد وازه ها: گر ايشهاى اجتماعى مطلوب، برستار، مراقبت، نوع دوستى

تعارض منافع : ندارد تاريخ دريافت: تاريخ بذيرش: تاريخ درياف:

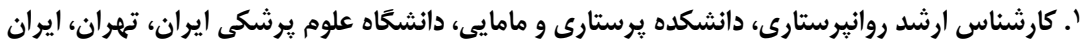

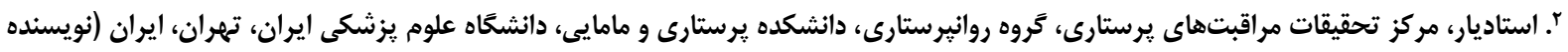
Email: mardanihamoole.m@iums.ac.ir

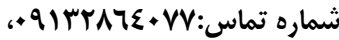

مسئول)

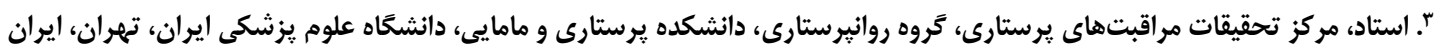

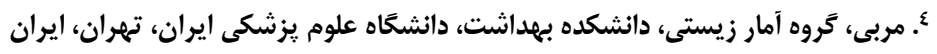


خرسند مىنمايد. اين امر منجر به مهربانى با ديخران، بروز

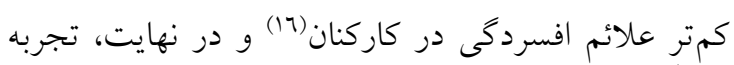

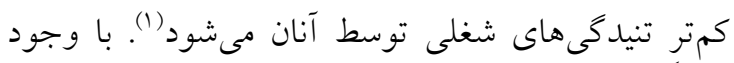

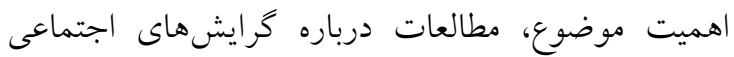
مطلوب در حرفه يرستارى، اندى مىباشند. با اين حال،

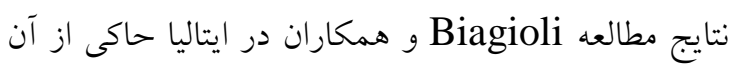

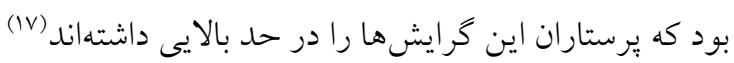

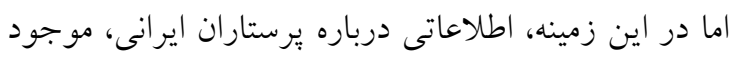
نيست. در حرفه يرستارى، اين كرايشها از ساختار

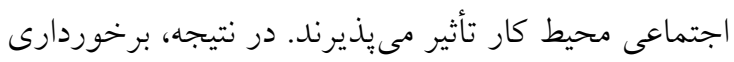

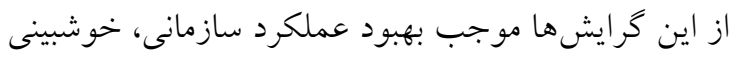

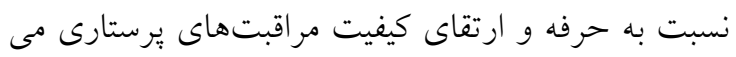

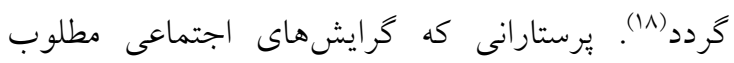
دارند، در محيط كار، مديريت بهترى بر رفتارهاى خود

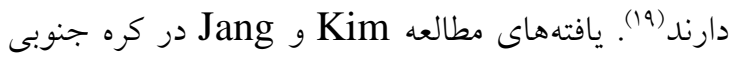
نشان داد كه برخوردارى از گرايشهاى اجتماعى مطلوب، خشنودى از ارتباطات سازمانى را براى برستاران به ارمغان

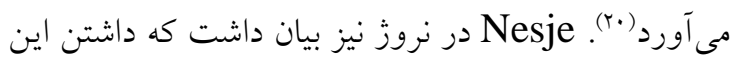
كرايشها، تعهد حرفهاى يرستاران را ارتقاء مىبخشد (YI).

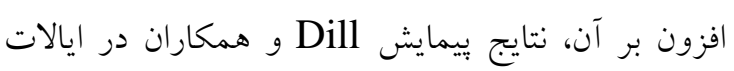

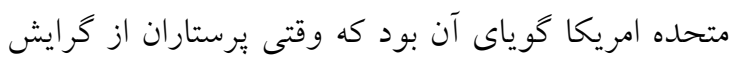

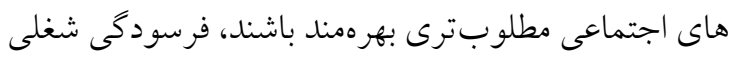

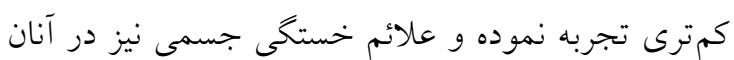

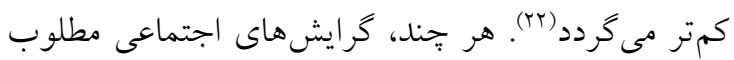
در حرفه يرستارى، كمتر مورد بررسى قرار كرفته اما از ميان

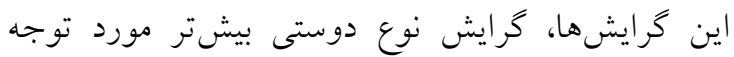

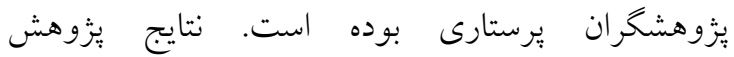
Mohammadi از بزرگترين ارزشهاى اخلاقى در مراقبت از بيمار به

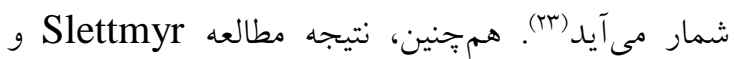

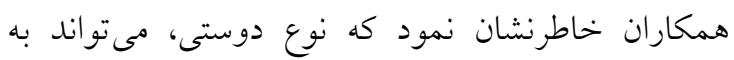
واسطه ارتقاى رويكردهاى مراقبتى بيمارمحور باعث تسهيل مراقبت انساندوستانه شود (ع).

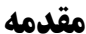

كرايشهاى اجتماعى مطلوب با هدف بهبود شرايط دريافت كننده كمك انجام مىشود و انخيزه شخصى كه مبادرت به جنين كارى مى كند، انجام تعهدات حرفهاى نيست. از طرفى، دريافت كننده كمك نيز يكى سازمان نبو نها

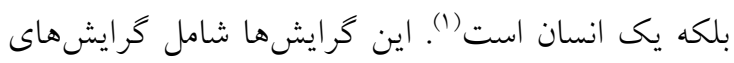
نوع دوستانه، متابعت آميز، هيجانى، بحرانى و ناشناس مى إنى

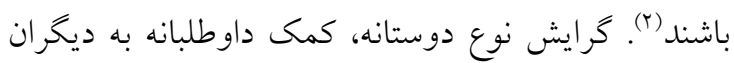

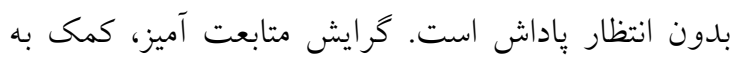

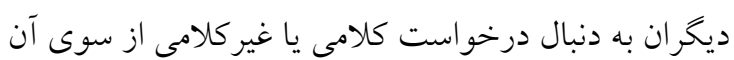

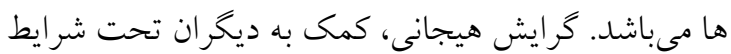

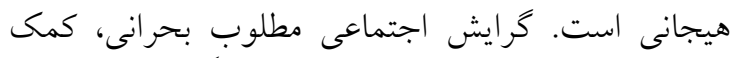
هايى است كه در شرايط بحرانى از افراد ديده مىشود و منظور از كرايش ناشناس، كمك به ديكران، بدون اين كه

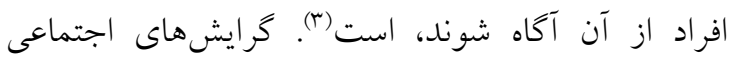
مطلوب، براى افراد، بهزيستى روانشناختى به ارمغان مى إنى

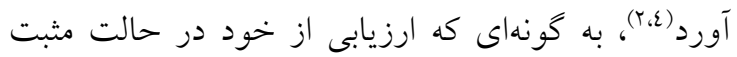

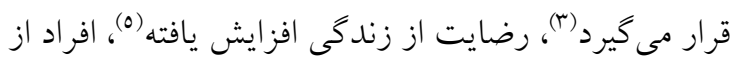

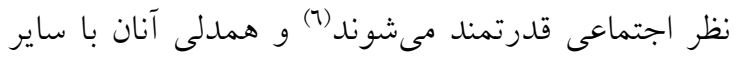

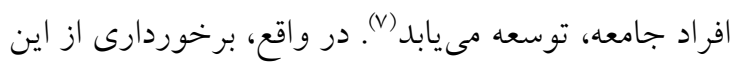

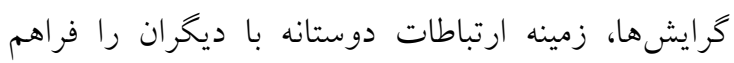

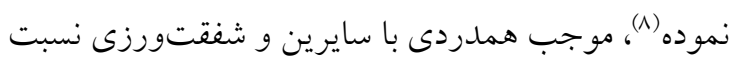
به آنان شده (9) و سبب حمايت از افراد نيازمند مى كردد (·.). در نتيجه، اين كرايشها موجب شكوفايى اجتماعى افراد

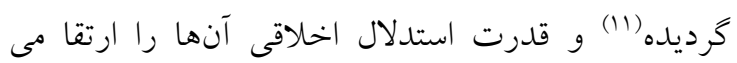

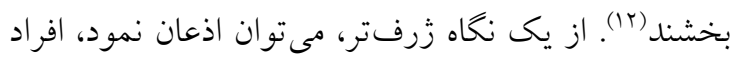

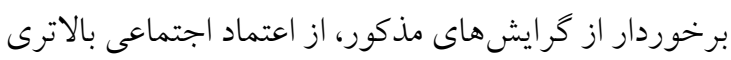
بهره مى برند و در نهايت، سلامت روانى - اجتماعى مطلوبى

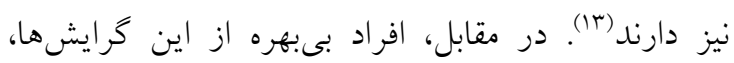

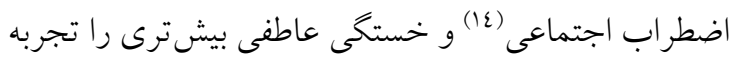
نموده و از كمكرسانى به ديخران و همدردى با آنان، احساس ناتوانى مى كند (10). بهرهمندى از گرايش هاى اجتماعى مطلوب، خشنودى حرفى حرفه اى كاركنان را ارتقاء داده و آنان را از ارتباط با ديخران، 
تعيين شد. بر اين اساس، از مراكز رسول اكرم (ص) و

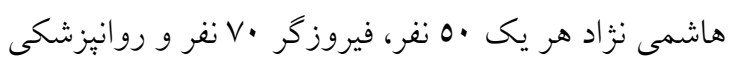

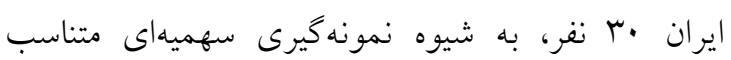

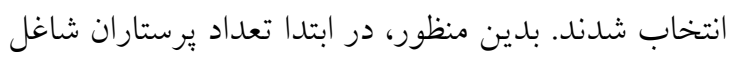

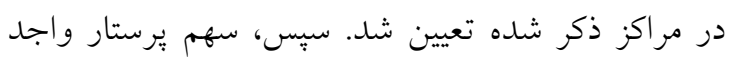

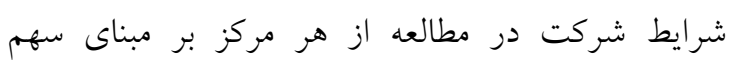
درصدى مشخص شد كه اين سهم براى مراكز رسول اكرم

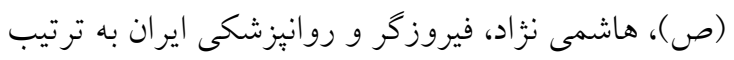

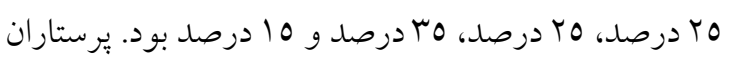

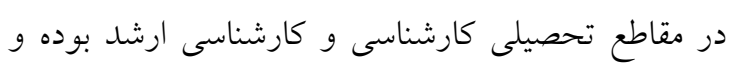

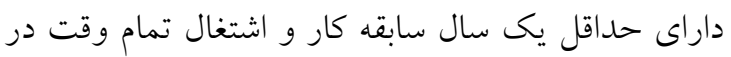

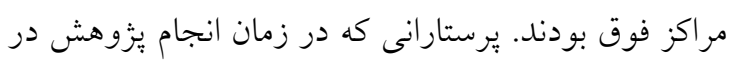

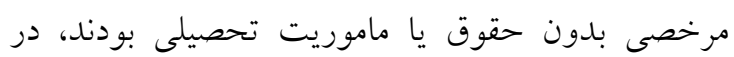
مطالعه شركت داده نشدند.

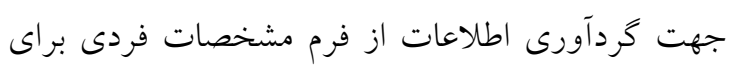
سنجش متغيرهاى سن، جنسيت، وضعيت تأهل، سطح

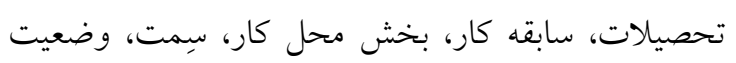

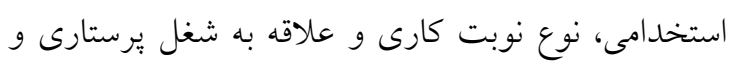

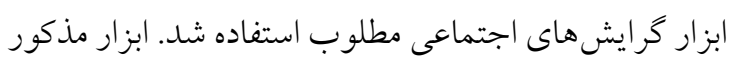

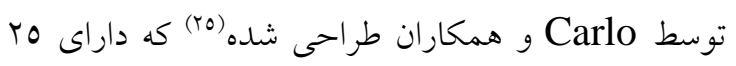

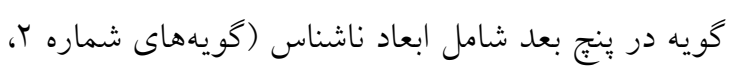

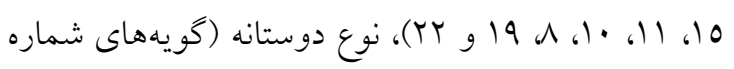

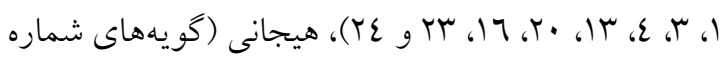

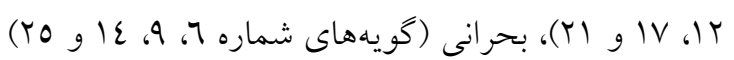

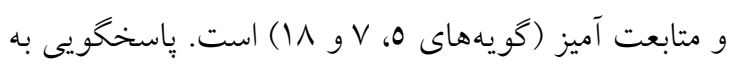

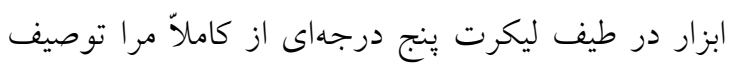

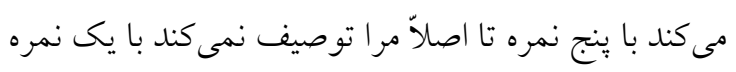

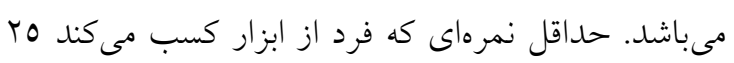

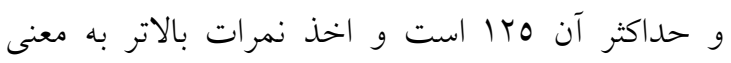
كرايشهاى اجتماعى مطلوب در وضعيت بهتر است. اين ابزار در ايران، روانسنجى شده و ضريب آلفاى كرونباخ

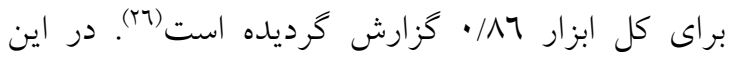
مطالعه نيز جهت سنجش روايى ابزار از شيوه روايى محتوا

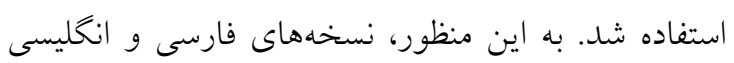

به جرات مىتوان اذعان نمود بهرهمندى از كرايشهاى

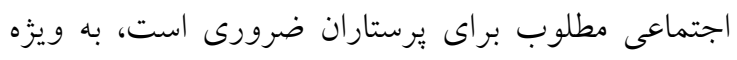

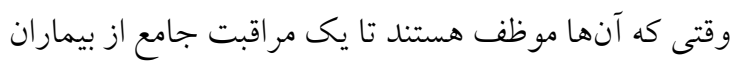

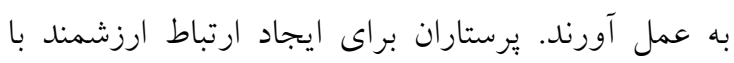

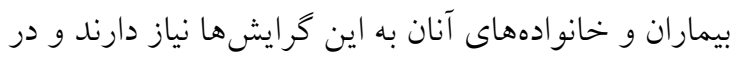
نهايت، اين گرايشها، سببساز استعلاى اخلاقى برستاران

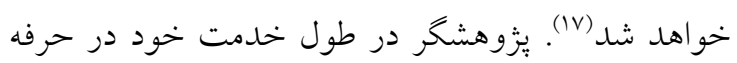
يرستارى، مشاهده نموده كه يكى از عوامل مهم در زمينه

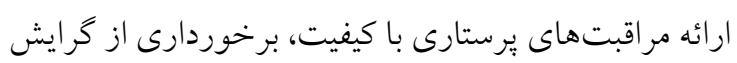

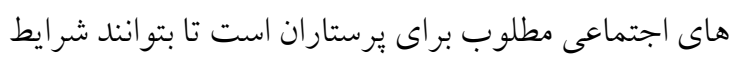
بيماران را به خوبى درى و مراقبت بهينه را به آنان ارائه

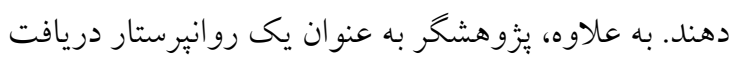

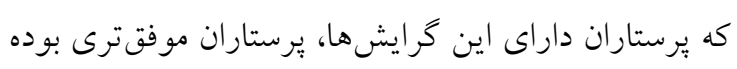

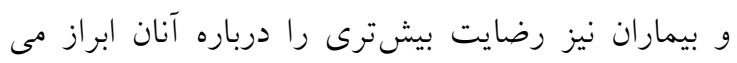

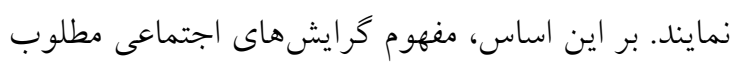

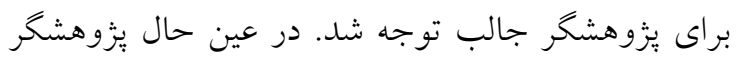

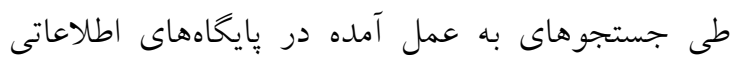

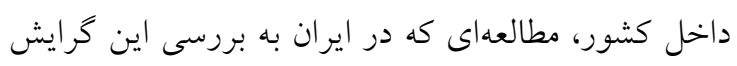

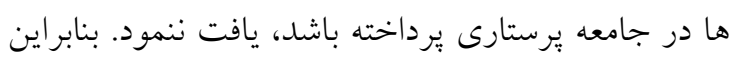

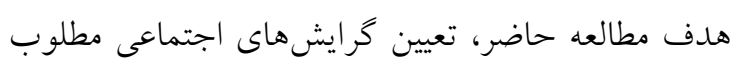
در ميان برستاران بود.

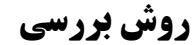

اين مطالعه توصيفى - مقطعى با دريافت مجوز از كميته

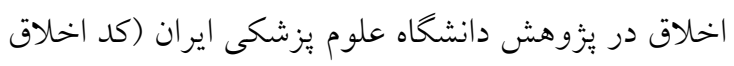

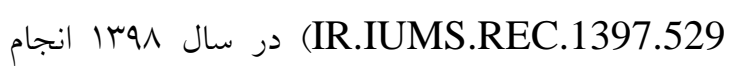
شد. ابتدا فهرستى از مراكز آموزشى درمانى وابسته به

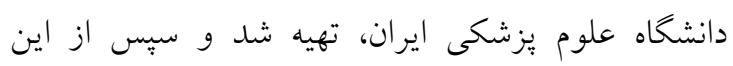
فهرست، به شيوه تصادفى ساده با قرعه كشى، جهار مركز

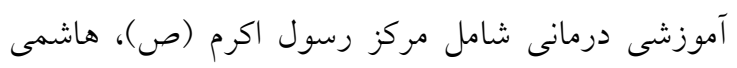

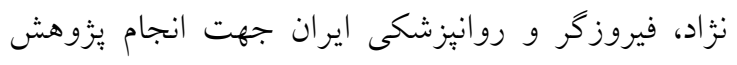
انتخاب شدند. جامعه يزوه هش شامل تمامى ير ستار ان شاغل

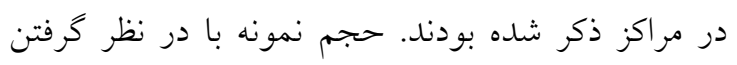

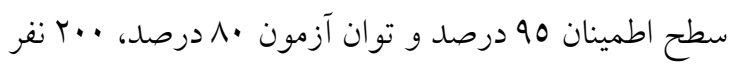


از آمار توصيفى (فراوانى، درصد، ميانخين و انحر افمعيار)

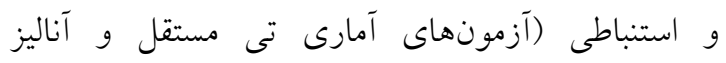
واريانس) تحت نرمافزار SPSS كمتر از ه• value

\section{يافتهها}

شاخصهاى عددى گر ايشهاى اجتماعى مطلوب برستاران بر حسب مشخصات فردى در جدول شماره ا نمايان است

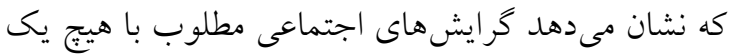
از اين مشخصات ارتباط معنى دار آمارى نداشت.
ابزار در اختيار ينج نفر از اساتيد صاحب نظر يرستارى قرار

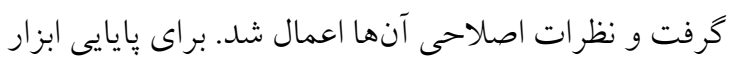

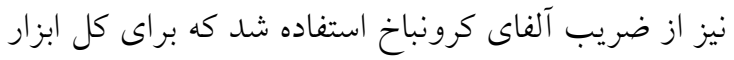

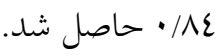

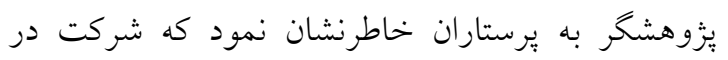
مطالعه اختيارى است و در زمينه حفظ اطلاعات به آنها اطمينان داد. سبس با مراجعه به بخشهاى محل كار يرستاران در نوبتهاى سه كانه صبح، عصر و شب به

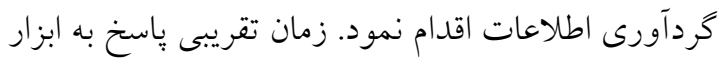

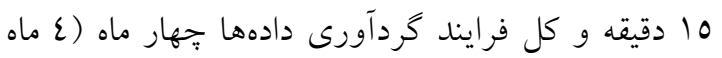
اول سال وهץ|) بود. تجزيه و تحليل دادهها با بهره كيرى

جدول شماره (: شاخصهاى عددى كَايش هاى اجتماعى مطلوب يرستار ان بر حسب مشخصات فردى

\begin{tabular}{|c|c|c|c|c|c|c|}
\hline نتيجه آزمون & انحر اف معيار & ميانگين & درصد & فر اوانى & \multicolumn{2}{|c|}{ مشخصات فردى } \\
\hline$F=\cdot / M T r$ & $10 / T Y$ & $\Lambda \Lambda \cdot \wedge$ & $\varepsilon V$ & $9 \varepsilon$ & كمتر از •r & \\
\hline \multirow[t]{2}{*}{$\mathrm{P}=\cdot / \mathrm{V} T O$} & $10 / v 0$ & NN/ᄉT & щ & $\sqrt{ } \mathrm{I}$ & $r \cdot-\varepsilon \cdot$ & سن (سال) \\
\hline & $|V / 7|$ & $\Lambda T / 1 \Gamma$ & 10 & $r$. & بيشتر از • ع & \\
\hline $\mathrm{t}=\cdot / \neg \varepsilon 1$ & $10 / 20$ & $\Lambda / \Sigma O$ & $\vee 9 / 0$ & 109 & زن ان & جنسيت \\
\hline $\mathrm{P}=\cdot / 0 r r$ & $17 / 94$ & $\wedge \top / \uparrow$ & $T \cdot 10$ & $\varepsilon 1$ & 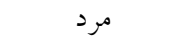 & \\
\hline $\mathrm{t}=\cdot / 7 \mathrm{rr}$ & $1 r / \wedge 9$ & $19 / 17$ & $\varepsilon r$ & $\wedge \varepsilon$ & مجرد & وضعيت تأهل \\
\hline $\mathrm{P}=\cdot /$ / 0. & $r \cdot / \mu r$ & $\wedge \varepsilon / V \backslash$ & $0 \wedge$ & 117 & متأهل & \\
\hline$t=1 / 1 r 7$ & $10 / 17$ & $\Lambda \Lambda / 7 \mu$ & $\wedge \varepsilon$ & 171 & كارشناسى & سطح تحصيلات \\
\hline \multirow[t]{2}{*}{$\mathrm{P}=\cdot / r 71$} & $1 N / \varepsilon 9$ & $10 / T_{1}$ & 17 & MT & كارشناسى ارشد & \\
\hline & $10 / 00$ & $\Lambda \mathrm{V} / \Lambda \Lambda$ & ro & $v \cdot$ & كمتر از 0 & \\
\hline $\mathrm{F}=\cdot / 771$ & $1 \varepsilon / 0 \varepsilon$ & $19 / \vee 9$ & $r \varepsilon$ & ऑ & $0-1$ & سابقه كار (سال) \\
\hline $\mathrm{P}=\cdot / 0 \mathrm{VV}$ & $1 \mathrm{~V} / \cdot 1$ & $\wedge V / \Lambda$ & m & $7 r$ & بيشتر از • & \\
\hline \multirow[b]{3}{*}{$\mathrm{F}=\cdot / \varepsilon \mid r$} & $r \cdot / \varepsilon 0$ & $\Lambda \mathrm{V} / \mathrm{\Lambda}$ & $T M / 0$ & $\varepsilon V$ & داخلى و جراحى & \\
\hline & $|N / \varepsilon|$ & $\Lambda V / O \varepsilon$ & rq & $\vee \wedge$ & ويزه و اورزانس & \\
\hline & IV/Tr & $\Lambda N / 9 \varepsilon$ & N/O & IV & كودكان & بخش محل كار \\
\hline \multirow[t]{2}{*}{$\mathrm{P}=\cdot / \wedge \mathrm{V} \mid$} & $1 r / \varepsilon 9$ & $19 / 19$ & $1 \varepsilon$ & r^ & ز زنان & \\
\hline & $1 \pi / \Lambda$ & $\Lambda \vee \mu$ & 10 & $r \cdot$ & روانيزشكى & \\
\hline $\mathrm{F}=\bullet / / \varepsilon \wedge$ & $10 / 0 \varepsilon$ & $M N / r$ & 90 & 19. & يرستار & \\
\hline \multirow[t]{3}{*}{$\mathrm{P}=\cdot / \wedge 7 \pi$} & $1 \varepsilon / \Lambda r$ & $M N / 9 T$ & $r$ & 7 & سريرستار & سمت \\
\hline & $r \cdot / r \Lambda$ & $\Lambda T / \varepsilon \mu$ & r & $\varepsilon$ & سويروايزر & \\
\hline & $10 / 17$ & $\Lambda T / \mu \vee$ & Or & $1 \cdot \varepsilon$ & قراردادى & \\
\hline $\mathrm{F}=r / \cdot 0 \wedge$ & $15 / 97$ & $\Lambda \top / \mu \wedge$ & $10 / 0$ & M & طرحى & وضعيت استخدامى \\
\hline \multirow[t]{2}{*}{$\mathrm{P}=\cdot / 1 \cdot \mathrm{V}$} & $19 / 77$ & $\Lambda / \mu\urcorner$ & $9 / 0$ & 19 & ييمانى & \\
\hline & $1 \varepsilon / r$ & 94 & rr & $\varepsilon 7$ & رسمى & \\
\hline
\end{tabular}




\begin{tabular}{|c|c|c|c|c|c|c|}
\hline $\mathrm{t}=1 / \mathrm{r} \times \mathrm{u}$ & $17 / T \wedge$ & $\wedge 0 / 1 \varepsilon$ & rI & $\varepsilon r$ & ثابت & نوبت كارى \\
\hline $\mathrm{P}=\cdot / / \mathrm{V} r$ & $10 / 00$ & $\Lambda \Lambda / \Lambda \vee$ & va & 101 & در گردش & \\
\hline $\mathrm{t}=\cdot / \mathrm{v}$ or & $17 \cdot r$ & $\Lambda \Lambda / \varepsilon \varepsilon$ & $\wedge \varepsilon / 0$ & 179 & بله & علاقه به شغل پرستارى \\
\hline $\mathrm{P}=\cdot / \varepsilon$ or & $1 \varepsilon / 1 V$ & $\wedge T / 1\rangle$ & $10 / 0$ & M & خير & \\
\hline
\end{tabular}

ها را براى يرستاران مورد ارزيابى قرار داده باشد، يافت نشد اما نتايج مطالعهاى در اصفهان كه به مطالعه كرايش هاى اجتماعى مطلوب در ميان دانشجويان شاغل به تحصيل در رشتههاى علوم يزشكى برداخت، نشان داد كه ميانخين

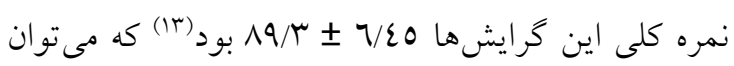
اظهار نمود تا حدودى با ئزوهش حاضر همسويى دارد. ابزار استفاده شده در مطالعه اخير با ابزار استفاده شده در "يزوهش حاضر، يكسان بود. در مطالعه كنونى، از ديدگاه برستاران، گرايشهاى اجتماعى مطلوب در بعد ناشناس با ميانخين 1/N/ بالاترين نمره را در بين ساير ابعاد داشتند. همسو با نتايج اين بخش از مطالعه، نتايج بررسى اين كرايشها در بين دانشجويان شاغل به تحصيل در رشتههاى علوم يزشكى شهر اصفهان نيز حاكى از آن بود كه اين كرايشها در بعد ناشناس، بالاترين ميانخين نمره را در ميان

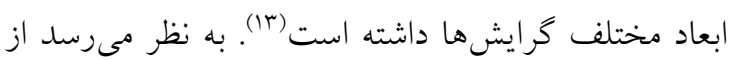
نخاه يرستاران شركت كننده در مطالعه حاضر، در ميان كرايشهاى اجتماعى، مطلوبترين آنها، كمكرسانى به ديخران است، بلدون اين كه دريافت كنندگان كمك از اين مهم آكاه باشند. شايد ريشه اين امر به ماهيت حرفه

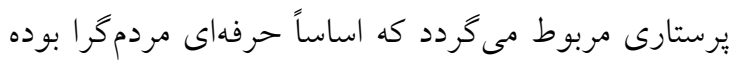
و شاغلين اين حرفه بر آنند تا به افراد جامعه خدمات ارائه دهند، حتى اخر افراد جامعه از اين موضوع بى اطلاع باشند.

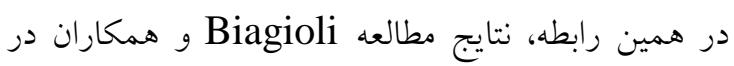

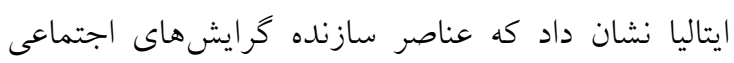
مطلوب در حرفه يرستارى شامل كمكى به ديخران و سهيم شدن با آنان مىباشند (IV). در مطالعه حاضر، گرايشهاى اجتماعى مطلوب در بعد بحرانى، دومين گرايش حائز اهميت از ديد گاه برستاران بود در حالى كه نتايج مطالعه اين گرايشها از نخاه دانشجويان رشتهاى علوم يزشكى شهر اصفهان، حكايت نمود كه
ساير نتايج نشان داد نمره كلى كرايشهاى اجتماعى

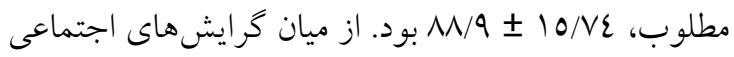

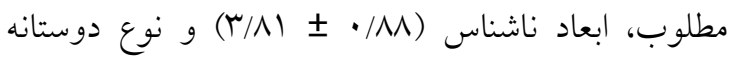
(Y/10 ب به ترتيب داراى بيشترين و كمترين ميانخين نمره بودند (جدول شماره Y).

\begin{tabular}{|c|c|c|}
\hline انحر اف معيار & ميانخين & كرايشهاى اجتماعى \\
\hline$\cdot / \Lambda \Lambda$ & $\mathrm{r} / \Lambda 1$ & شناس \\
\hline$\cdot / 9 r$ & $r / v \varepsilon$ & بحرانى \\
\hline $1 / 1$ & r/VT & هيجانى \\
\hline$\cdot / \mathrm{V} \wedge$ & $r / \neg \Lambda$ & متابعتآميز \\
\hline$\cdot / A Y$ & $r / 10$ & نوع دوستانه \\
\hline
\end{tabular}

\section{بحث و نتيجه كيرى} اين مطالعه با هدف تعيين گرايشهاى اجتماعى مطلوب درى يرستاران انجام شد. يافتها نشان داد كه نمره كلى اين

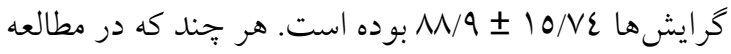

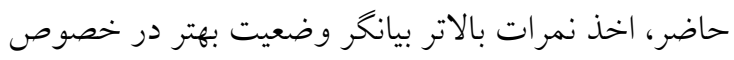
كرايشهاى اجتماعى مطلوب است اما نمره كلى كسب

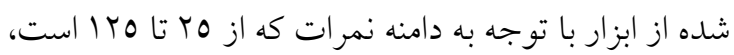
در حد قابل قبولى به نظر مىرسد. در همين رابطه، نتايج مطالعه Biagioli و همكاران در ايتاليا نشان داد كه با در نظر گرفتن نمرات از ا تا ه براى گويههاى ابزار، ميانگين نمره يرستاران در خصوص گر ايشهاى اجتماعى مطلوب، r/99 بوده كه نشانه بالا بودن كرايشهاى ياد شده براى يرستاران بود (IV). لازم به ذكر است كه در مطالعه ذكر شده از ابزار ديخرى براى سنجش گرايشهاى ياد شده استفاده

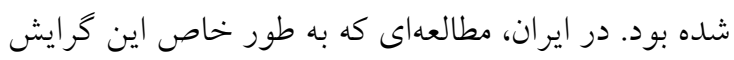


قرار گرفتن بعد نوع دوستى در بايين ترين ابعاد از گرايش

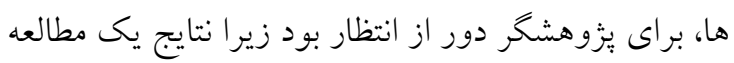

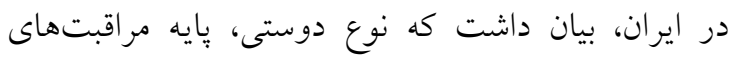

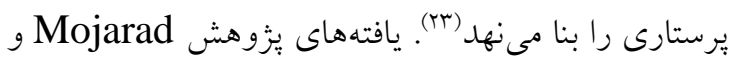

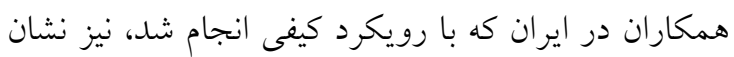
داد كه طبق تجارب يرستاران، عواملى كه تسهيل كننده حضور برستار در كنار بيمار مىباشند، مشتمل بر نوع

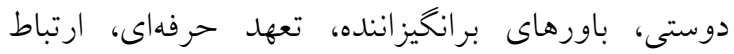

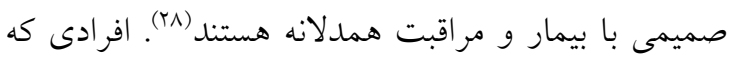
كرايشهاى نوع دوستانه كمترى دارند، به همان نسبت،

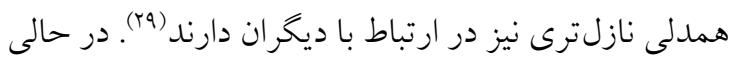
كه همدلى به عنوان يكى سازه روانشناختى، اجازه مى دهد

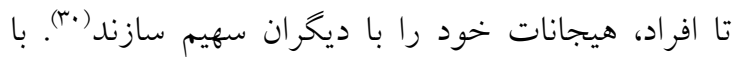

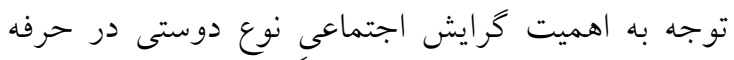

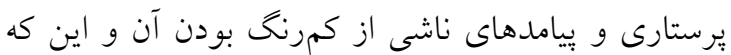
در مطالعه حاضر، اين گرايش اجتماعى مطلوب در نازل ترين وضعيت از ديدكاه يرستاران قرار كرفته است،

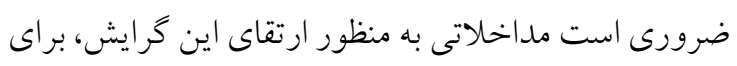

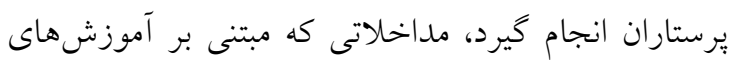

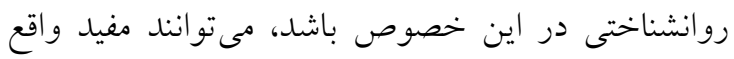

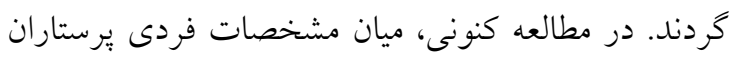

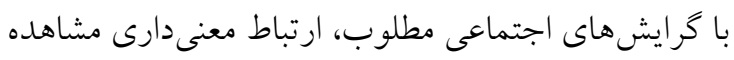

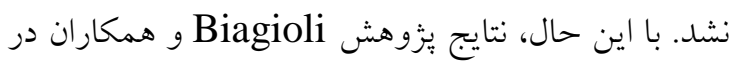

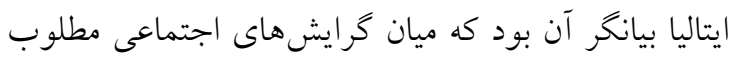
با سطح تحصيلات يرستاران ارتباط معنىدار وجود دارد

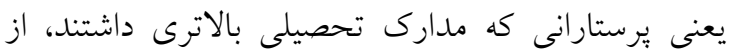
كرايشهاى اجتماعى مطلوبترى نيز برخوردار بودند (IV).

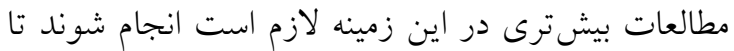
بتوان با قطع و يقين درباره ارتباط ميان مشخصات فردى

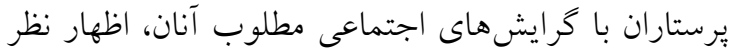

به طور كلى، هر جنند، مطالعات اندكى در زمينه كرايشهاى

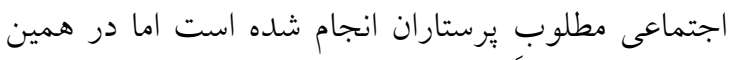
مطالعات اندى نيز بين نتايج يزوهش حاضر بـ با نتايج آن
كرايش نوع دوستى، دومين گرايش حائز اهميت بوده

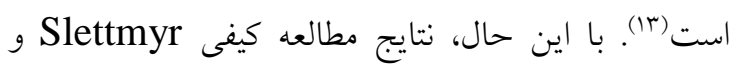

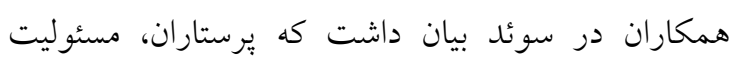
يذيرى بدون قيد و شرط در قبال افراد جامعه دارند. به به بهن

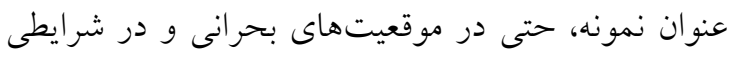
كه سلامتى، زندكى و امنيت شخصى يرستار ان به مخاطره

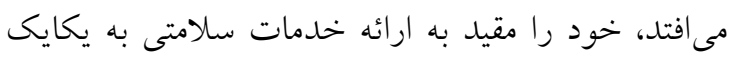

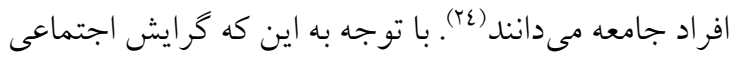
مطلوب در بعد بحرانى دربردارنده كمكهايى است كه در شرايط بحرانى از افراد ديده مىشود، اين گرايش از نخاه

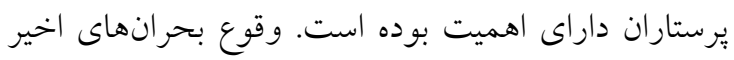
در كشورمان نيز بر اين مهم، صحه كذاشته است كه يرستاران در زمان شرايط بحرانى مثل زلزله و سيل، خود را موظف مى دانند كه به يارى افراد جامعه بشتابند. ساير نتايج يُزوهش حاضر، نشان داد كه كرايشهاى اجتماعى مطلوب

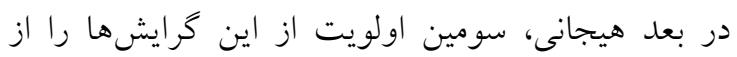

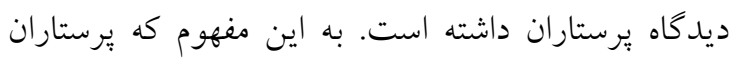
كمك به ديخران را تحت شرايط هيجانى مد نظر قرار داده

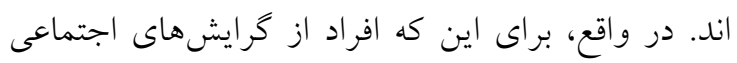
مطلوب، بهرهمند باشند، بايد درى هيجانى بالايى داشته آنه

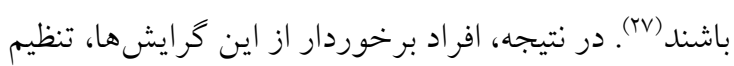
هيجانى بهترى داشته و و اكنشهاى هيجانى خود را بهتر

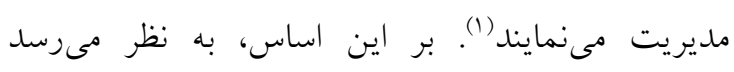

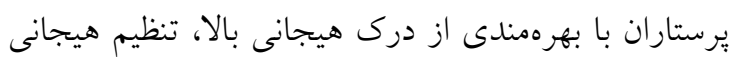

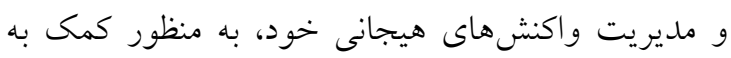
ديخران تحت شرايط هيجانى، اقدام مىنمايند.

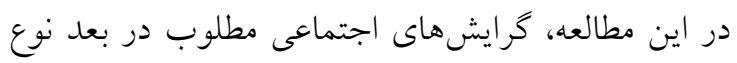
دوستانه، پايينترين ميانكين نمره را در بين ساير ابعاد

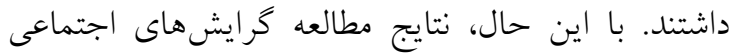
مطلوب در بين دانشجويان شاغل به تحصيل در رشتههاى علوم يزشكى شهر اصفهان، بيان داشت كه اين گرايشها

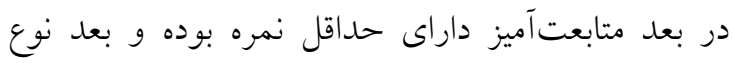

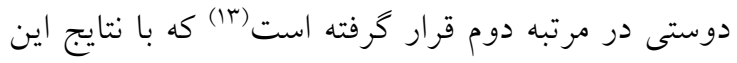

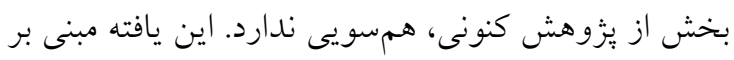




$$
\begin{aligned}
& \text { اجتماعى مطلوب در نظر گيرند كه ابعاد گوناگون اين } \\
& \text { يزوهشها همسويى قاطعى وجود ندارد كه اين امر لزوم } \\
& \text { كرايشها در عناصر سازنده مدل مذكور، لحاظ شوند. }
\end{aligned}
$$

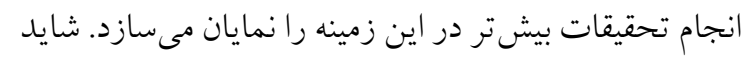

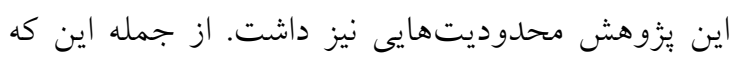

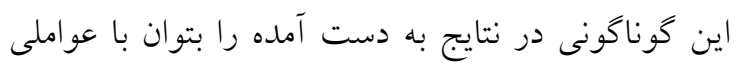

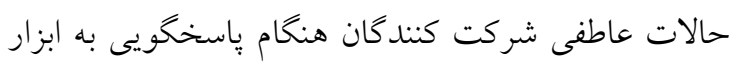

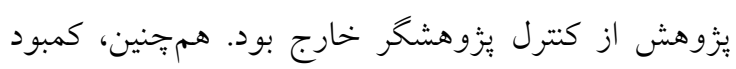

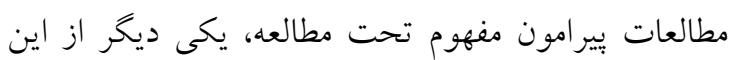

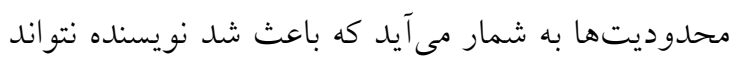

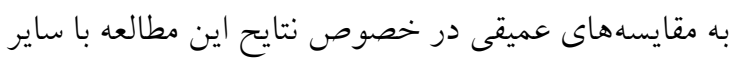

$$
\begin{aligned}
& \text { مطالعات مشابه، اقدام نمايد. } \\
& \text { تضاد منافع: هيج گونه تضاد منافع از سوى نويسندگان }
\end{aligned}
$$

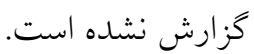

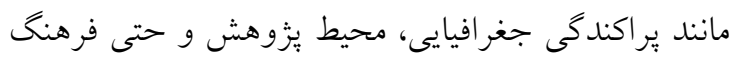

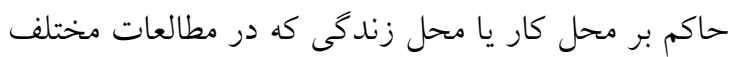

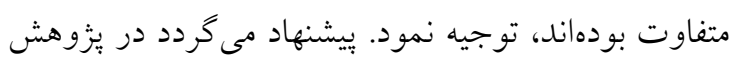

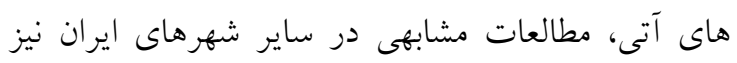

$$
\begin{aligned}
& \text { توسط محققان يرستارى انجام شود تا بتوان در اين } \\
& \text { خصوص به مقايسه نتايج برداخت. به علاوه، توصيه مى }
\end{aligned}
$$

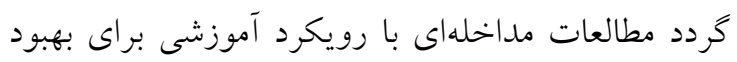

$$
\begin{aligned}
& \text { نخرش برستاران در خصوص كرايشهاى اجتماعى نوع }
\end{aligned}
$$

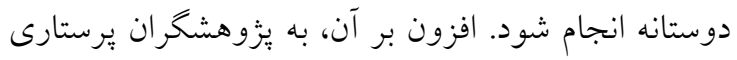

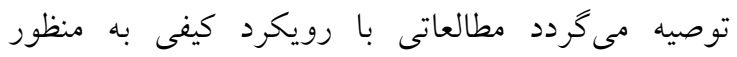

$$
\begin{aligned}
& \text { تقدير و تشكر }
\end{aligned}
$$

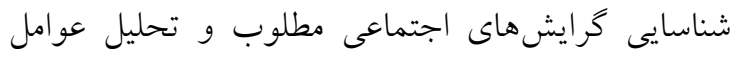

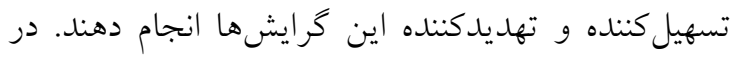

$$
\begin{aligned}
& \text { عرصه يرستارى بالينى، نتايج اين مطالعه مىتواند مورد }
\end{aligned}
$$

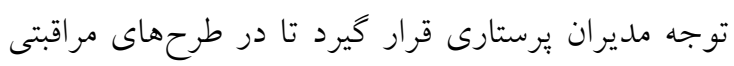

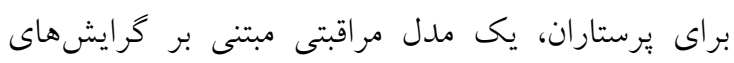

شود.

\section{References}

1. Bailey PE, Brady B, Ebner NC, Ruffman T. Effects of age on emotion regulation, emotional empathy, and prosocial behavior. J Gerontol: Series B. 2018 Jul 17.

2. Morelli SA, Knutson B, Zaki J. Neural sensitivity to personal and vicarious reward differentially relate to prosociality and well-being. Soc Cog Affect Neurosci. 2018;13(8):831-9.

3. Carlo G, Basilio CD, Knight GP. The associations of biculturalism to prosocial tendencies and positive self evaluations. J Lat psychol. 2016;4(4):189-201.

4. Serrat EG, González-Carrasco M, Casas FA, Malo SC. Prosociality as a Form of Productive Aging: Predictors and Their Relationship With Subjective Well-Being. Res Gerontol Nurs. 2018;11(6):306-15.

5. Reich WA, Sangiorgio C, Young J. Self-Role Integration: A Person-Specific Predictor of Life Satisfaction and Prosocial Behavior. The Journal of psychology. 2019;153(6):649-66.

6. Fu X, Lv Y, Yang Z, Yu X, Wang R. Chinese adolescents' power distance value and prosocial behavior toward powerful people: A longitudinal study. PloS one. 2018;13(12):e0208473.

7. Franzen A, Mader S, Winter F. Contagious yawning, empathy, and their relation to prosocial behavior. J Exp Psychol Gen. 2018;147(12):1950-8.

8. Freitas M, Santos AJ, Ribeiro O, Daniel JR, Rubin KH. Prosocial behavior and friendship quality as moderators of the association between anxious withdrawal and peer experiences in Portuguese young adolescents. Front Psychol. 2018;9:2783.

9. Lamm C, Rütgen M, Wagner IC. Imaging empathy and prosocial emotions. Neurosci lett. 2019;693:49-53.

10. Shaver PR, Mikulincer M, Cassidy J. Attachment, behavior in the wider world. Curr Opin Psychol. 2019;25:16-20. 
11. Moradi S, Van Quaquebeke N, Hunter JA. Flourishing and prosocial behaviors: A multilevel investigation of national corruption level as a moderator. PloS one. 2018;13(7):e0200062.

12. Nooien A, Kajbaf MB, Foroudastan M. Prosocial Behaviorsand Altruism among Citizens of Isfahan. Journal of Applied Sociology. 2013;50(2):49-54. [Persian]

13. Afghari F, Ghasemi S. The Relationship between Social Trust and Prosocial Tendencies. Iranian Journal of Psychiatric Nursing. 2015;3(2):62-71. [Persian]

14. von Dawans B, Trueg A, Kirschbaum C, Fischbacher U, Heinrichs M. Acute social and physical stress interact to influence social behavior: The role of social anxiety. PloS one. 2018;13(10):e0204665.

15. Park YN, Hyun H, Jhang J. Do Emotional Laborers Help the Needy More or Less? The Mediating Role of Sympathy in the Effect of Emotional Dissonance on Prosocial Behavior. Front Psychol. 2019;10:118.

16. Chancellor J, Margolis S, Jacobs Bao K, Lyubomirsky S. Everyday prosociality in the workplace: The reinforcing benefits of giving, getting, and glimpsing. Emotion. 2018;18(4):507.

17. Biagioli V, Prandi C, Giuliani L, Nyatanga B, Fida R. Prosocial behaviour in palliative nurses: psychometric evaluation of the prosociality scale. Int J Palliat Nurs. 2016;22(6):292-8.

18. Feather J, McGillis Hall L, Trbovich P, Baker GR. An integrative review of nurses' prosocial behaviours contributing to work environment optimization, organizational performance and quality of care. Journal of nursing management. 2018;26(7):769-81.

19. Tuyen LT, Gunawan J. Behavior management in the field of nursing: A concept analysis. InNursing forum 2018 ; 53(4: 481-8.

20. Kim Y, Jang SJ. Nurses' organizational communication satisfaction, emotional labor, and prosocial service behavior: A cross-sectional study. Nursing \& health sciences. 2019 ;21(2):223-30.

21. Nesje K. Nursing students' prosocial motivation: does it predict professional commitment and involvement in the job?. J Adv Nurs. 2015;71(1):115-25.

22. Dill J, Erickson RJ, Diefendorff JM. Motivation in caring labor: Implications for the well-being and employment outcomes of nurses. Social Science \& Medicine. 2016 1;167:99-106.

23. Mohammadi A, Vanaki Z, Memarian R, Fallahrafie RA. Islamic and Western Ethical Values in Health Services Management: A Comparative Study. Int J Nurs Knowl. 2019, 30(4):239-50.

24. Slettmyr A, Schandl A, Arman M. The ambiguity of altruism in nursing: A qualitative study. Nursing ethics. 2019;26(2):368-77.

25. Carlo G, Hausmann A, Christiansen S, Randall BA. Sociocognitive and behavioral correlates of a measure of prosocial tendencies for adolescents. The journal of early adolescence. 2003;23(1):107-34.

26. Kajbaf MB, Sajjadian I, Nouri A. A Study of Factor Structur, Validity And Reliabileaty of ProSocial Tendencies Measure Revised Questionnaire among University Students. Journal of Applied Sociology. 2010; 21(2):101-18. [Persian]

27. Eckland NS, Huang AB, Berenbaum H. Empathic accuracy: Associations with prosocial behavior and self-insecurity. Emotion. 201913.

28. Mojarad FA, Sanagoo A, Jouybari L. Exploring the experiences of oncology nurses about the factors facilitating their presence at the bedside of patients with cancer: A qualitative study. Indian J Palliat Care. 2019;25(2):236-41.

29. Mayer SV, Jusyte A, Klimecki-Lenz OM, Schönenberg M. Empathy and altruistic behavior in antisocial violent offenders with psychopathic traits. Psychiatry research. 2018 1;269:625-32.

30. Sivaselvachandran S, Acland EL, Abdallah S, Martin LJ. Behavioral and mechanistic insight into rodent empathy. Neurosci Biobehav Rev. 2018 1;91:130-7. 